\title{
Stability Evolution of a Large Rock Block Revealed in the Excavation Process of the Left Slope of Jinping-I Hydropower Station Based on the Proposed Sarma's Method
}

\author{
Tao Chen ${ }^{1, a}$, Guanhua Sun ${ }^{2, b}$, Hong Zheng ${ }^{1,2, c}$ \\ ${ }^{1}$ College of Civil Engineering and Architecture, China Three Gorges University, Yichang, Hubei \\ 443002, China \\ ${ }^{2}$ State Key Laboratory of Geomechanics and Geotechnical Engineering, Institute of Rock and Soil \\ Mechanics, Chinese Academy of Sciences, Wuhan, Hubei 430071, China \\ a tchen0928@163.com , ${ }^{\mathrm{b}}$ ghsun@whrsm.ac.cn, ${ }^{\mathrm{c}}$ hzheng@whrsm.ac.cn
}

Keywords: Sarma's method, Rock slope stability, Shear strength, Limit equilibrium.

Abstract. There is a latent large block near the dam abutment of Jinping-I hydropower station, the stability of which is very important in the excavation process. As we know, Sarma's method is able to evaluate the stability of rock slopes with complex structural planes, because it takes into account the mobilization of internal strength of potential landslides. In the presence of multiple rock layers, however, no unified way is available to calculate the total strength on the slice interface, although in most cases the equivalent strength parameters are taken as the weighted averages of strength parameters of all layers. From the assumption that the normal pressure along the slice interface takes on a triangular distribution, we derive the equivalent strength parameters of the slice interface. Moreover, we discuss the influence of different selections of equivalent strength parameters of the slice interface on the factor of safety of a rock slope from a hydropower station in construction, with the conclusion that the difference might be appreciable. At last, based on the proposed procedure the stability evolution of the large rock block in excavation process is discussed. Its stability is increased before elevation $1840 \mathrm{~m}$ is reached because the upper portions of the blocks are removed, which help slide. After that, however, the stability is decreased gradually because the lower anti-sliding portions are removed little by little, which help stabilize the slip bodies. After the sliding body is wholly revealed, the factor of safety is 2.83, which is higher than that of sliding body corresponds to the dam crest and lower than that of the maximum in excavation process.

\section{Introduction}

The Jinping-I hydropower station is located in the west of Great River Bend of Yalong River, Sichuan Province, China. Electricity generation is one of main tasks of the huge hydropower station, with a total capacity of 3600MW. Another important task of the project is flood-control for Yangtze River. The capacity of reservoir under the normal pool level and regulation storage is $77.6 \times 10^{8}$ and $49.1 \times 10^{8}$ $\mathrm{m}^{3}$ respectively. The concrete double curvature arch dam of Jinping-I is the highest arch dam in the world with the dam height of $305 \mathrm{~m}$, the crest width of $16 \mathrm{~m}$, bottom thickness of $63 \mathrm{~m}$ and volume of dam 474 ten thousands $\mathrm{m}^{3}$.

The original geomorphology is a dip angle of $40-45^{\circ}$. As indicated in the engineering geology conditions of the left bank, there is a latent large block near the dam abutment generated by fault $\mathrm{f}_{42-9 \text {, }}$ lamprophyre vein $X$ and fracturing band $\mathrm{SL}_{44-1}$, as shown in Fig. 1 . The fault fracturing zone $\mathrm{f}_{42-9}$ with occurrence $\mathrm{N} 80^{\circ} \mathrm{E} \sim \mathrm{EW} / \mathrm{SE}(\mathrm{S}) \angle 40 \sim 55^{\circ}$ is composed of breccia, mylonite and some fault gouge. The lamprophyre vein with occurrence $\mathrm{N} 60 \sim 80^{\circ} \mathrm{E}, \mathrm{SE} \angle 70 \sim 90^{\circ}$ and width 1.5-3.0 $\mathrm{m}$ has poor weather resistance. The fissure $\mathrm{SL}_{44-1}$ has the occurrence $\mathrm{SN} \sim \mathrm{N} 20^{\circ} \mathrm{W}, \mathrm{E}(\mathrm{NE}) \angle 55 \sim 60^{\circ}$. 


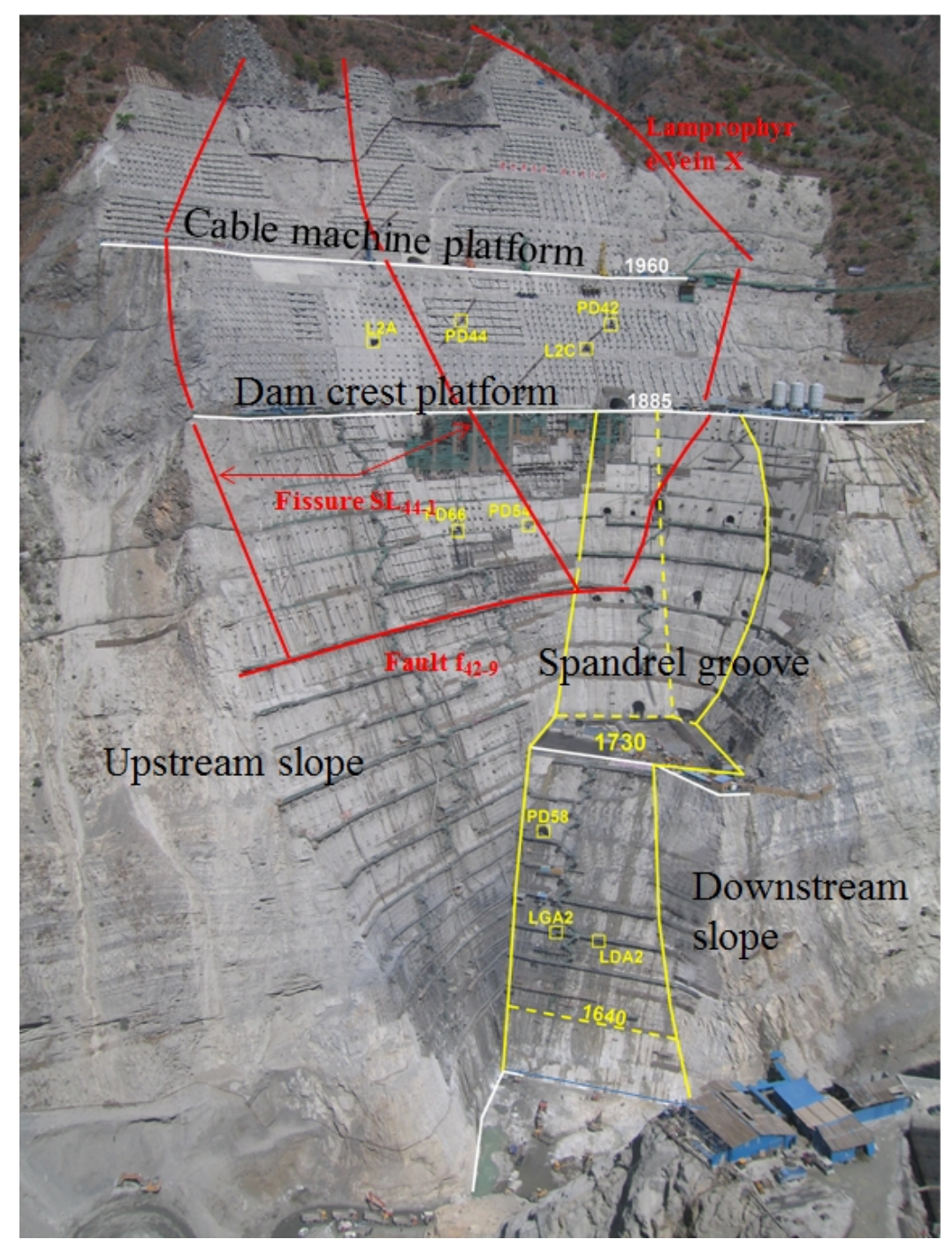

Fig. 1 The left bank rock slope of Jinping-I Hydropower Station after excavation

For this large rock block, some researchers and engineers have analyzed its stability. The comprehensive method incorporating microseismic monitoring and numerical analysis has proven very promising in instability prediction of the left bank slope of Jinping-I by Xu et al. [1]. On the basis of the equivalent acceleration and Sarma's method [2], the high rock slopes on the left bank in the Jinping I Hydropower Station are analyzed [3]. The engineering geological research of the left bank in the Jinping I Hydropower Station can be supplied by some relevant references [4 5]. The stability evolution due to excavation of the left bank rock slope of Jinping-I Hydropower Station is systematically studied with an improved block theory by Sun et al. [6].

As we know, Sarma's method is very applicable to the analysis of rock slopes. In the setting of the limit equilibrium methods, Sarma developed the method of slant slices to calculate the magnitude of a horizontal seismic coefficient needed to bring the failure mass into the limit equilibrium state. The static factor of safety can be derived through an iteration process, where the factor of safety is defined as the strength reduction factor that corresponds to a critical seismic coefficient of zero.

In recent years, many scholars have carried out more deep research on Sarma's method. Bafghi et al. [7] proposes an extension to the key-block method, which combines not only individual key-blocks but also groups of collapsable blocks into a progressive analysis of the stability of discontinuous rock slopes. From a more concise process, Zhu et al. [8] derived the implicit expression for the factor of safety, the explicit expressions of the critical seismic coefficient and the critical reinforcing load factor, respectively. By means of Cramer's rule, Jie et al. [9] deduced a general analytical expression of Sarma's acceleration. Furthermore, for four commonly used slice methods 
with simple relations in the forces on each slice and Sarma's acceleration, a general closed-form solution of Sarma's acceleration was given. Based on a realistic mobilization of interslice shear forces, Yang et al. [10] discussed two possible directions of interslice shear force in Sarma's method.

In this study, on the basis of engineering geological conditions and the analysis of excavation process, the expressions for the equivalent strength parameters of slice interfaces are deduced from the assumption that the normal pressure along the slice interface takes on a triangular distribution. Then, the influences of the equivalent strength parameters determined by the proposed procedure and the weighted average method (WAM) on the factor of safety are discussed with a high and steep slope of a hydropower project as an example.

\section{Methodology}

One fundamental assumption in Sarma's method is that not only the slip surface but the slice interfaces arrive at the limit equilibrium state simultaneously, which needs to calculate the total shear strength on each slice interface. If there is only one material above the slip surface, as in Sarma [2], no problem exists for such a calculation. If not, no unified way is available to calculate the total shear strength along the slice interface. Sarma and Tan [11] proposed that the weighted averages of strength parameters of all layers on a slice interface be taken as the equivalent strength parameters in the calculation of the total strength of the slice interface, which is referred to as the weighted average method (WAM) subsequently. WAM, in our opinion, is not justified. In this study, from the assumption that the normal pressure along the slice interface takes on a triangular distribution, the expressions for the equivalent strength parameters of a slice interface are deduced. Then, the influences of the equivalent strength parameters determined by the proposed procedure and WAM on the factor of safety are discussed.

As shown in Fig. 2, the $i$-th slice in Sarma's method is drawn for the force analysis. From the force equilibrium condition for slice- $i$ in vertical and horizontal directions, two equations can be obtained:

$$
\begin{aligned}
& N_{i} \cos \alpha_{i}+T_{i} \sin \alpha_{i}=W_{i}+X_{i+1} \cos \beta_{i+1}-X_{i} \cos \beta_{i}-E_{i+1} \sin \beta_{i+1}+E_{i} \sin \beta+T V_{i} \\
& T_{i} \cos \alpha_{i}-N_{i} \sin \alpha_{i}=K W_{i}+X_{i+1} \sin \beta_{i+1}-X_{i} \sin \beta_{i}+E_{i+1} \cos \beta_{i+1}-E_{i} \cos \beta_{i}-T H_{i}
\end{aligned}
$$

with the seismic coefficient $K$. Here, $T V_{i}$ and $T H_{i}$ are vertical and horizontal components of reinforcement force $T_{i}$; and other notations are marked in Fig. 2.

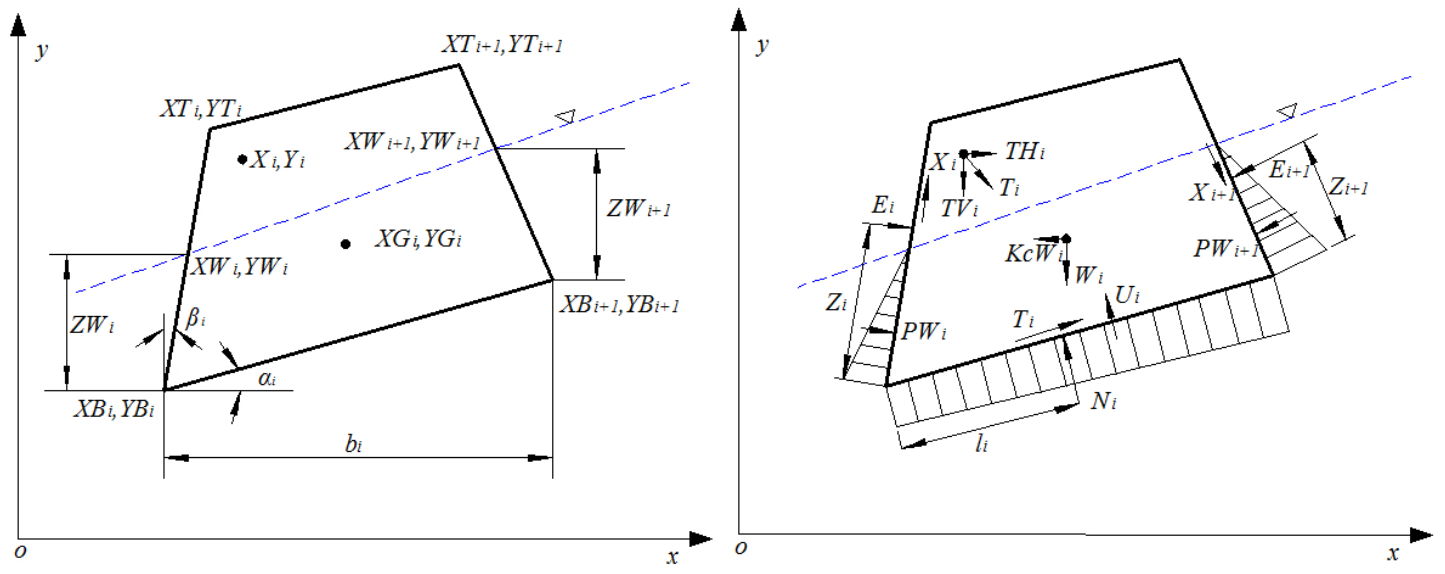

Fig.2 Sketch for geometry (left) and forces (right) of a typical slice

Sarma [2] assumed that as the seismic coefficient $K$ arrives at the critical value $K_{c}$, not only the slip surface but also the slice interfaces will arrive at the limit equilibrium state simultaneously, suggesting that

$$
T_{i}=\left(N_{i}-U_{i}\right) \tan \varphi_{i}+c_{i} b_{i} \sec \alpha_{i}
$$




$$
\begin{aligned}
& X_{i}=\left(E_{i}-P W_{i}\right) \bar{f}_{i}^{j}+\bar{c}_{i}^{j} d_{i} \\
& X_{i+1}=\left(E_{i+1}-P W_{i+1}\right) \bar{f}_{i+1}^{j}+\bar{c}_{i+1}^{j} d_{i+1}
\end{aligned}
$$

Here, $d_{i}$ and $d_{i+1}$ are lengths of two interfaces of slice-i; $c_{i}$ and $\phi_{i}$ are cohesion and friction angle of the slice basis; $\bar{c}_{i}^{j}$ and $\bar{f}_{i}^{j}$ are the equivalent cohesion and friction factor of the $i$-th slice interface and to be discussed in the next section. All strength parameters are in terms of effective stress.

Substituting Eq.3 5 into Eq. 1 2 and performing a readjustment, we have the critical seismic coefficient $K_{c}$,

$$
K_{c}=\frac{E_{1} e_{n} e_{n-1} \cdots e_{3} e_{2} e_{1}+\left(a_{n}+a_{n-1} e_{n}+a_{n-2} e_{n} e_{n-1}+\cdots+a_{1} e_{n} e_{n-1} \cdots e_{3} e_{2}\right)-E_{n+1}}{p_{n}+p_{n-1} e_{n}+p_{n-2} e_{n} e_{n-1}+\cdots+p_{1} e_{n} e_{n-1} \cdots e_{3} e_{2}}
$$

where,

$$
\begin{aligned}
& a_{i}=Q_{i}\left[\left(W_{i}+T V_{i}\right) \sin \left(\varphi_{i}-\alpha_{i}\right)-T H_{i} \cos \left(\varphi_{i}-\alpha_{i}\right)\right. \\
& \left.+R_{i} \cos \varphi_{i}+S_{i+1} \sin \left(\varphi_{i}-\alpha_{i}-\beta_{i+1}\right)-S_{i} \sin \left(\varphi_{i}-\alpha_{i}-\beta_{i+1}\right)\right] \\
& p_{i}=Q_{i} W_{i} \cos \left(\varphi_{i}-\alpha_{i}\right) \\
& e_{i}=Q_{i}\left[\cos \left(\varphi_{i}-\alpha_{i}+\varphi_{i}^{j}-\beta_{i}\right) \sec \varphi_{i}^{j}\right] \\
& Q_{i}=\frac{1}{\cos \left(\varphi_{i}-\alpha_{i}+\varphi_{i+1}^{j}-\beta_{i+1}\right) \sec \varphi_{i+1}^{j}} \\
& S_{i}=c_{i}^{j} d_{i}-P W_{i} \tan \varphi_{i}^{j} \\
& S_{i+1}=c_{i+1}^{j} d_{i+1}-P W_{i+1} \tan \varphi_{i+1}^{j} \\
& R_{i}=c_{i}^{j} b_{i} \sec \alpha_{i}-U_{i} \tan \varphi_{i} \\
& \text { with } \bar{f}_{i}^{j}=\tan \phi_{i}^{j} \text { and } \bar{f}_{i+1}^{j}=\tan \phi_{i+1}^{j} .
\end{aligned}
$$

For a multilayer rock slope, a natural question arises: how to determine the strength parameters of the slice interfaces in Eq. 4 5. Sarma and Tan [11] proposed taking the weighted averages of the materials on the interfaces. In our opinion, it is not justified.

In this section, we assume that the normal pressure between two neighboring slices takes on a triangular distribution, as shown in Fig. 3. This is a commonly accepted assumption in geotechnical engineering, such as the theory on lateral pressure and retaining walls [12].

Now let's suppose that there are total $m$ layers crossed by the slice interface of interest. $D_{k}$ is the distance from the bottom of the $k$-th layer to the ground surface, with $D_{0}=0$ and $D_{m}=d$-- the length of the slice interface.

By using the trapezoid integration formula, we have the resultant normal force acting at the $k$-th layer, 


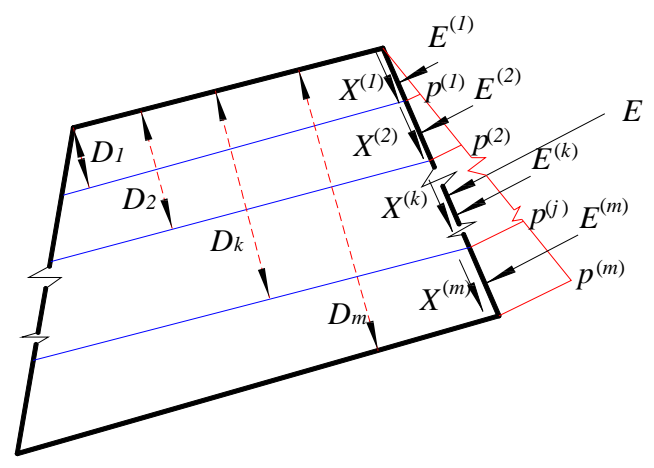

Fig.3 Sketch for geometry and forces between slices of the multilayer rock masses

$$
E^{(k)}=\frac{D_{k}^{2}-D_{k-1}^{2}}{D_{m}^{2}} E, \quad 1 \leq k \leq m
$$

With $E$ represents the total normal force at the slice interface. The Mohr-Coulomb criterion says that on the $k$-th layer,

$$
X^{(k)}=c^{(k)}\left(D_{k}-D_{k-1}\right)+E^{(k)} f^{(k)}, 1 \leq k \leq m
$$

Here, $c^{(k)}$ and $\varphi^{(k)}$ are the strength parameters of layer- $k$ in the slice interface.The total shear force reads

$$
X=\sum_{k=1}^{m} X^{(k)}=\sum_{k=1}^{m}\left[c^{(k)}\left(D_{k}-D_{k-1}\right)+E^{(k)} f^{(k)}\right]
$$

Substitution of Eq. 7in Eq.9 leads to

$$
X=E \bar{f}+\bar{c} d
$$

The equivalent cohesion $\bar{C}$ is the same as WAM,

$$
\bar{c}=\frac{1}{d} \sum_{k=1}^{m}\left(D_{k}-D_{k-1}\right) c^{(k)}
$$

but the equivalent friction factor $\bar{f}$ is given by

$$
\bar{f}=\frac{1}{d^{2}} \sum_{k=1}^{m}\left(D_{k}^{2}-D_{k-1}^{2}\right) f^{(k)}
$$

different from that by WAM, which reads

$$
\bar{f}_{\text {WAM }}=\frac{1}{d} \sum_{k=1}^{m}\left(D_{k}-D_{k-1}\right) f^{(k)}
$$

Clearly, unless $f^{(k)}=$ constant or $m=1, \bar{f} \neq \bar{f}_{\text {WAM }}$.

On the basis of the parameters of shear strength of the left bank of the dam crest platform high slope on elevation 1885m and below in the Jinping-I Hydropower Station, a sliding mode of section 1-1 of the left bank high slope is selected in this study to analyze the stability under the reasonable parameter of shear strength. The sliding mode is shown in Fig. 4, and the slip surface passes through a fault named f8 and a weak unloading boundary. The potential landslide is divided into a total of 7 inclined slices. 


\section{0m}

$1885 \mathrm{~m}$

Potential

Landslide

6

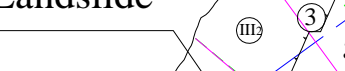

5

4

3

Fig.4 Sliding mode of the left bank slope of the Jinping-I Hydropower Station

Geometry and strength parameters of all slices and slice interfaces are listed in Table 1.

Table 1 Geometry and strength parameters of the slices

\begin{tabular}{|c|c|c|c|c|c|c|c|c|c|}
\hline \multicolumn{10}{|c|}{ Slice Interfaces } \\
\hline \multicolumn{2}{|l|}{ No. } & 1 & 2 & 3 & 4 & 5 & 6 & 7 & 8 \\
\hline \multicolumn{2}{|c|}{$X T(\mathrm{~m})$} & 0 & 15.75 & 30.92 & 61.51 & 79.66 & 102.74 & 123.76 & 165.2 \\
\hline \multicolumn{2}{|l|}{$Y T(\mathrm{~m})$} & 1704.54 & 1743 & 1763.39 & 1822.67 & 1855 & 1854 & 1885 & 1885 \\
\hline \multicolumn{2}{|c|}{$X B(\mathrm{~m})$} & 0 & 24.36 & 60.38 & 127.07 & 136.22 & 142.32 & 157.91 & 165.2 \\
\hline \multicolumn{2}{|c|}{$Y B(\mathrm{~m})$} & 1704.54 & 1713.3 & 1732.29 & 1767.31 & 1777.73 & 1800.34 & 1858.32 & 1885 \\
\hline \multirow{3}{*}{ III $_{\text {II }}$} & $D_{1}$ & 1 & 30.91 & 15.81 & 27.14 & 41.75 & 27.83 & 43.33 & 1 \\
\hline & $\varphi\left(^{\circ}\right)$ & 1 & 38.7 & 38.7 & 38.7 & 38.7 & 38.7 & 38.7 & 1 \\
\hline & $c(\mathrm{kPa})$ & 1 & 800 & 800 & 800 & 800 & 800 & 800 & 1 \\
\hline \multirow{3}{*}{$\mathrm{III}_{1}$} & $D_{2}$ & I & 30.91 & 42.84 & 85.71 & 95.75 & 66.6 & 43.33 & 1 \\
\hline & $\varphi\left(^{\circ}\right)$ & 1 & 45.6 & 45.6 & 45.6 & 45.6 & 45.6 & 45.6 & 1 \\
\hline & $c(\mathrm{kPa})$ & 1 & 1000 & 1000 & 1000 & 1000 & 1000 & 1000 & 1 \\
\hline \multicolumn{2}{|c|}{$c_{i}^{j}(k P a)$} & I & 1000 & 926.19 & 936.745 & 912.79 & 916.43 & 1000 & I \\
\hline Proposed & $\varphi_{i}^{j}\left(^{\circ}\right)$ & 1 & 38.70 & 44.75 & 44.25 & 44.40 & 44.50 & 38.70 & I \\
\hline $\begin{array}{l}\text { Weighted } \\
\text { Average }\end{array}$ & $\varphi_{i}^{j}\left(^{\circ}\right)$ & l & 38.70 & 43.23 & 42.60 & 42.78 & 42.90 & 38.70 & I \\
\hline \multicolumn{10}{|c|}{ Slices } \\
\hline \multicolumn{2}{|c|}{ No. } & 1 & 2 & 3 & 4 & 5 & 6 & 7 & 1 \\
\hline \multicolumn{2}{|c|}{$\gamma_{i}\left(k N / m^{3}\right)$} & 27 & 27 & 27 & 27 & 27 & 27 & 27 & I \\
\hline \multicolumn{2}{|l|}{$\varphi_{i}\left(^{(}\right)$} & 45.6 & 45.6 & 45.6 & 33 & 16.7 & 16.7 & 16.7 & 1 \\
\hline \multicolumn{2}{|c|}{$c_{i}(k P a)$} & 1000 & 1000 & 1000 & 500 & 20 & 20 & 20 & 1 \\
\hline
\end{tabular}


If the proposed method in the last section is employed, the factor of safety of the sliding body is 2.79 and the critical seismic coefficient $K_{c}$ is 0.4661 . The two values are 2.77 and 0.4480 respectively if the equivalent strength parameters of the slice interfaces are taken as ones determined by WAM.

For the above case, the difference in both the factor of safety and the critical seismic coefficient is a trifle between the proposed procedure and WAM. However, the difference will increase as the differences in the friction angles of different layers become large.

\section{Stability Evolution of a Large Rock Block Revealed in the Excavation Process}

From the geological conditions and proposed method stated above, another six models with the excavated benches are also shown in Fig.5. In order to analyze the change of safety factors with excavation, 7 sliding bodies for excavated models are created respectively, each of which corresponds to an excavation elevation. Step-1-sliding body corresponds to the dam crest with elevation $1885 \mathrm{~m}$; Step-2-sliding body to elevation $1870 \mathrm{~m}$; Step-3-sliding body to elevation $1855 \mathrm{~m}$; Step-4-sliding body to elevation 1840 m; Step-5-sliding body to elevation 1825 m; Step-6-sliding body to elevation $1810 \mathrm{~m}$; and Step-7-sliding body to the wholly revealed state. According to geological conditions, the material parameters of the slip surfaces are listed in Table 1.

The factors of safety of the seven models during excavation are shown in Fig. 5. It can be seen that the stability is increased before elevation $1840 \mathrm{~m}$ is reached, because the upper portions of the blocks are removed, which help slide. After that, however, the stability is decreased gradually because the lower anti-sliding portions are removed little by little, which help stabilize the slip bodies. After the sliding body is wholly revealed, the factor of safety is 2.83 , which is higher than that of sliding body corresponds to the dam crest and lower than that of the maximum in excavation process.

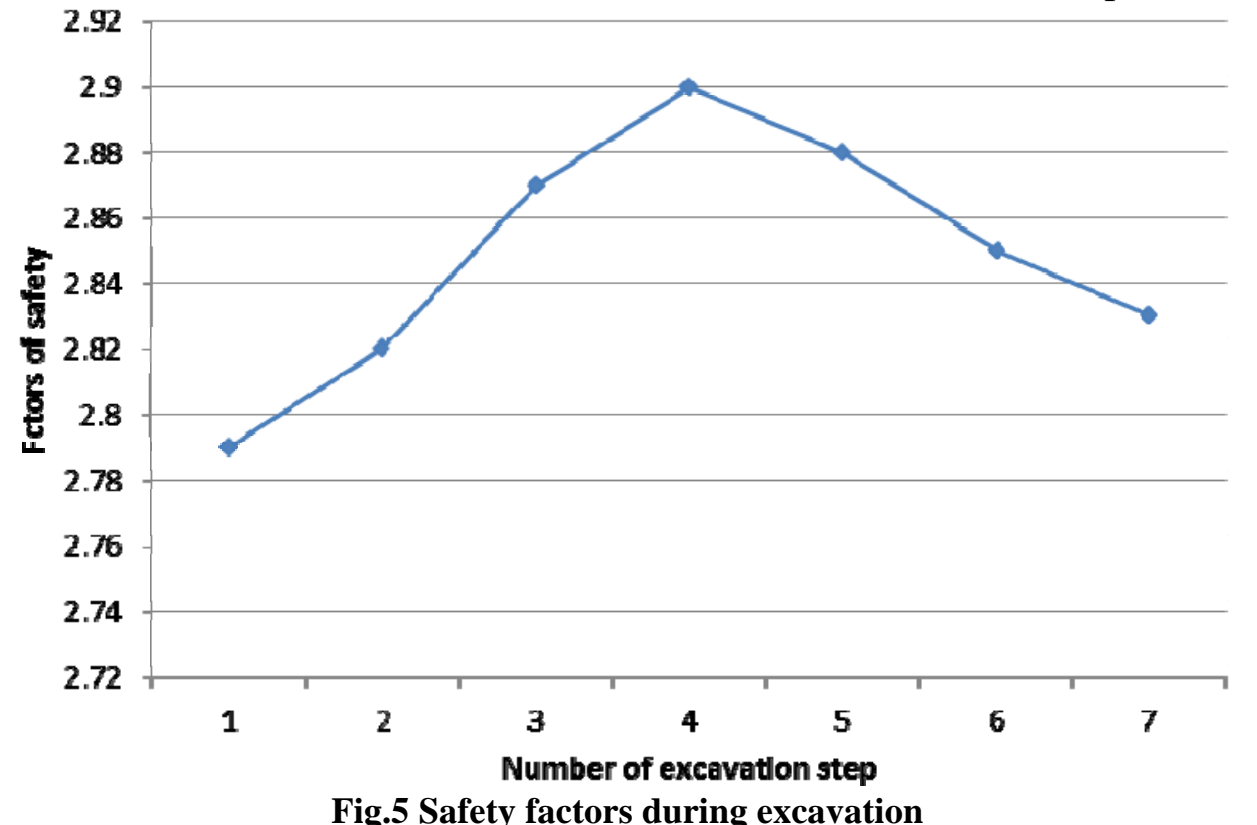

\section{Summary}

As we know, Sarma's method is very applicable to the analysis of rock slopes. In the presence of multiple rock layers, however, no unified way is available to calculate the total strength on the slice interface, although in most cases the equivalent strength parameters are taken as the weighted averages of strength parameters of all layers. To sum up, some conclusions are following:

(1) For the multilayer rock slope, the values of the internal friction angles are connected with the normal pressure distribution.

(2) The stability of the large rock block revealed in the excavation process of the left slope of Jinping-I hydropower station is increased before elevation $1840 \mathrm{~m}$ is reached, because the upper 
portions of the blocks are removed, which help slide. After that, however, the stability is decreased gradually because the lower anti-sliding portions are removed little by little, which help stabilize the slip bodies.

(3) After the sliding body is wholly revealed, the factor of safety is 2.83, which is higher than that of sliding body corresponds to the dam crest and lower than that of the maximum in excavation process.

\section{Acknowledgements}

This work was financially supported by the national basic research program of China (973 Program, Grant No. 2011CB013505) and national natural science foundation of China (Grant No: 11202223).

\section{References}

[1] Xu NW, Tang CA, Li LC. Microseismic monitoring and stability analysis of the left bank slope in Jinping first stage hydropower station in southwestern China. International Journal of Rock Mechanics and Mining Sciences, 48(6):950-963. (2011)

[2] Sarma SK. Stability analysis of embankments and slopes. Geotechnique, 23: 423-433. (1973)

[3] Chen M, Lu WB, Yan P, Zhou CB. New method for dynamic stability analysis of rock slope underblasting vibration based on equivalent acceleration and Sarma method. Can. Geotech. J, 51: 441-448. (2014)

[4] Qi SW, Wu FQ, Zhou YD. Influence of deep seated discontinuities on the left slope of Jinping I Hydropower Station and its stability analysis. Bulletin of Engineering Geology and the Environment, 69(3):333-342. (2010)

[5] Huang RQ, Lin F, Yan M. Deformation mechanism and stability evaluation for the left abutment slope of Jinping I hydropower station. Bulletin of Engineering Geology and the Environment, 69(3):365-372. (2010)

[6] Sun GH, Zheng H, Huang YY. Stability analysis of statically indeterminate blocks in key block theory and application to rock slope in Jinping-I Hydropower Station. Engineering Geology, 186:57-67. (2015)

[7] Bafghi AR, Verdel T. Sarma-based key-group method for rock slope reliability analyses. Int. J. Numer. Anal. Meth. Geomech, 29:1019-1043. (2005)

[8] Zhu DY, Lee CF, Huang MS. Modification to three well-known methods of slope stability analysis. Chinese Journal of Rock Mechanics and Engineering, 24(2): 183-194. (2005)

[9] Jie M, Chen CY, Zhang JJ. General stability of two-dimensional slopes based on Sarma's method. Int. J. Numer. Anal. Meth. Geomech, 23: 413-426. (1999)

[10] Yang MC, Zheng YR. Discussion about the direction of interslice shear force in Sarma's method. Underground Space, 22(6):142-144. (2002)

[11] Sarma SK, Tan D. Determination of critical slip surface in slope analysis. Gètechnique, 56: 539-550. (2006)

[12] Aysen A. Soil mechanics: basic concepts and engineering applications. Taylor \& Francis, London. (2005) 